\title{
Inflation, inflation uncertainty and output growth: recent evidence from ASEAN-5 countries
}

\begin{abstract}
This paper investigates the links between inflation, its uncertainty and economic growth in five ASEAN countries over the period 1980: Q1-2011: Q3. We rely on the Exponential GARCH (EGARCH) model to explore the causal relationship among the three variables. The major findings are: (i) inflation uncertainty increases more in response to positive inflation surprises than to negative surprises in all countries; (ii) inflationary shocks affect positively inflation uncertainty as predicted by the Friedman-Ball hypothesis; (iii) there is no evidence to suggest that inflation uncertainty causes inflation and; (iv) there is evidence that inflation affects growth negatively, both directly and indirectly (via the inflation uncertainty channel). The indirect effect is clearly stronger as it applies in all countries in the sample.
\end{abstract}

Keyword: Inflation; Inflation uncertainty; Output growth; ASEAN 